\title{
EFEITO DO FOSFITO DE POTÁSSIO ISOLADO E EM MISTURA COM FUNGICIDAS NO CONTROLE DA REQUEIMA DO TOMATEIRO
}

\author{
J.G. Töfolii ${ }^{1}$, S.C. Mello², R.J. Domingues ${ }^{1}$ \\ ${ }^{1}$ Instituto Biológico, Centro de Pesquisa e Desenvolvimento de Sanidade Vegetal, Av. Cons. Rodrigues Alves, \\ 1252, CEP 04014-002, São Paulo, SP, Brasil. E-mail: tofoli@biologico.sp.gov.br
}

\section{RESUMO}

\begin{abstract}
Três experimentos foram realizados, um em casa-de-vegetação e laboratório e os demais em campo, com o objetivo de estudar a ação do fosfito de potássio isolado e em mistura com fungicidas

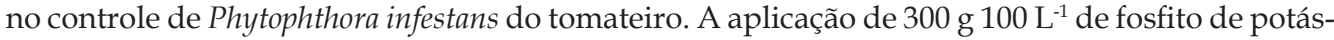
sio associado com mancozebe foi mais eficiente no controle da requeima nos cultivares 'Rebeca' e 'Giuliana', em relação à aplicação isolada desses produtos, no quarto e sétimo dia após a inoculação em discos foliares. No campo, clorotalonil/metalaxil-M + mancozebe/propamocarbe associados com fosfito de potássio nas doses de 100, 200 e $300 \mathrm{~g} 100 \mathrm{~L}^{-1}$ foram mais eficientes no controle da requeima que o cimoxanil + mancozebe/fenamidona/iprovalicarbe + propinebe e o uso isolado de fosfito de potássio. O uso de dimetomorfe + mancozebe + fosfito de potássio reduziu drasticamente a severidade da doença quando comparado à aplicação isolada de mancozebe, de fosfito de potássio ou da mistura mancozebe + fosfito de potássio. A mistura entre mancozebe e fosfito de potássio (300 g $100 \mathrm{~L}^{-1}$ ) proporcionou maior controle da requeima em relação ao uso isolado.
\end{abstract}

PALAVRAS-CHAVE: Solanum lycopersicum, Phytophthora infestans, ácido fosforoso.

\section{ABSTRACT}

EFFECT OF POTASSIUM PHOSPHITE ALONE AND IN MIXTURE WITH FUNGICIDES ON THE CONTROL OF LATE BLIGHT IN TOMATO CROP. Three trials were carried out in the greenhouse and laboratory along with others in the field with the objective to study the effect of potassium phosphite with or without fungicides on the control of Phytophthora infestans in the

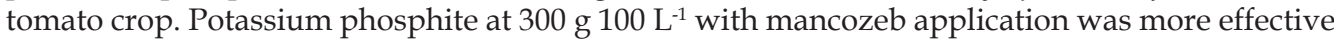
than products applied alone for the control of late blight of the tomatoes 'Rebeca' and 'Giuliana' on the 4 th and 7 th day after inoculation on leaf discs. In the field, clorotalonil/metalaxyl-M +

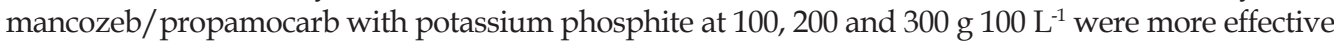
than cymoxanil + mancozeb/fenamidone/iprovalicarb + propineb and potassium phosphite alone in the control of late blight. Dimetomorph + mancozeb + potassium phosphite drastically decreased the disease severity as compared with mancozeb, potassium phosphite alone or mancozeb + potassium phosphite. The mixture of mancozeb and potassium phosphite (300 g 100 $\mathrm{L}^{-1}$ ) provided greater control of late blight as compared to its use in isolation.

KEY WORDS: Solanum lycopersicum, Phytophthora infestans, phosphorous acid.

\section{INTRODUÇAO}

A requeima, causada pelo oomiceto Phytophthora infestans, é uma das mais agressivas e destrutivas doenças do tomateiro em condições de alta umidade e temperaturas amenas (Kurozawa; Pavan, 2005; LOPES; AvILA, 2005).

Na ausência de materiais resistentes, o uso de fungicidas como metalaxil-M, cimoxanil, dimetomorfe, famoxadona, fenamidona, propamocarbe, piraclostrobina tem sido eficiente no controle da requeima do tomateiro e refletido de forma significativa sobre a produtividade e qualidade da produção (TöFOLI et al., 2003).

Entretanto, formas alternativas de controle têm sido pesquisadas, com o objetivo de reduzir os custos de produção e diminuir o impacto ambiental. Dentre elas, destaca-se o uso de produtos à base de fosfitos. Os fosfitos são compostos derivados do ácido fosforoso que podem se combinar com elementos como

${ }^{2}$ Universidade Estadual de São Paulo, Escola Superior de Agricultura "Luiz de Queiroz", Departamento de Produção Vegetal, Piracicaba, SP, Brasil. 
potássio, cálcio, magnésio, alumínio, manganês e zinco. Tais compostos caracterizam-se por estimular o crescimento das plantas (ANDREU et al., 2006; LovATT; MiKKelsen, 2006), possuírem considerável ação fungicida (COFFEY; BOWER, 1984; COHEN; COFFEY, 1986) e não serem fitotóxicos quando utilizados em concentrações adequadas.

Os fosfitos caracterizam-se pela sua eficiência no controle de míldios e diversas doenças causadas pelo gênero Phytophthora (OUIMETTE; COFFEY, 1989; WicKs et al., 1990). Apresentam ação sistêmica acropetal e basipetal e atuam na supressão de doenças foliares e radiculares (GUEST; GrANT,1991). Além disso, possuem alta estabilidade nas plantas, podendo permanecer ativos por períodos consideráveis (SMILLIE et al., 1989).

Quanto ao modo de ação dos fosfitos, alguns autores consideram a sua ação direta sobre o patógeno (Fenn; Coffey, 1984; Fenn; Coffey, 1985; McGrath, 2004). Outros acreditam que ela é indireta por meio da ativação dos mecanismos de defesa da planta (SAindRenAn et al., 1990; NeMESTOTHY; GUeST, 1990) ou ainda conjunta (SMILLIE et al., 1989; JACKSONetal., 2000).

A ação direta ou fungicida dos fosfitos é a mais relatada, enquanto que a de ativador de mecanismos de defesa das plantas é questionada, não se encontrando em muitos casos evidências de indução de resistência (RIBEIRO JUNIOR et al., 2006). Quanto à ação direta sobre o patógeno, sabe-se que o ácido fosforoso e seus derivados atuam na inibição do processo da fosforilação oxidativa em oomicetos (McGrath, 2004). Entre os fosfitos, o de potássio destaca-se por afetar mais o crescimento micelial de diferentes espécies de Phytophthora e apresentar maior solubilidade, quando comparado a outros produtos do grupo (OuimetTe; Coffey, 1989). Outra característica que reforça a importância da ação direta dos fosfitos é a sua ineficácia quando utilizados em raças de oomicetos resistentes a esta classe de produtos (Brown et al., 2004). O modo de ação direto e indireto dos fosfitos sobre Phytophthora cinnamomi foi relatado por JACKSON et al. (2000), onde esses, em altas concentrações, atuaram como inibidores diretos do patógeno e em baixas foram capazes de estimular a produção de enzimas de defesa do hospedeiro.

Estudos sobre a eficácia dos fosfitos sobre diferentes isolados de $P$. infestans verificaram a existência de uma grande variação na sensibilidade em função da variabilidade genética do patógeno (BASHAN et al., 1990; COFFEY; BOWER, 1984).

O fosfito de potássio tem apresentado ação positiva no controle de oomicetos em diversas hortaliças, como tomate e pimenta (FöRSTER et al., 1998), brássicas (BЕСОT et al., 2000), batata (JOHNSON et al., 2004; ANDReu et al., 2006), pepino (IRVING; Kúc, 1990), morango (Rebollar-Alviter et al., 2010) e alface (PAJот et al., 2001). Destaca-se, também, que os fosfitos nunca apresentam controle total da doença, sejam estes aplicados em caráter preventivo ou curativo (Ouimette; Coffey, 1989).

Várias formulações de fosfito de potássio têm sido comercializadas no Brasil, entretanto, poucos são os trabalhos que descrevem o seu potencial de ação e controle. Considerando a importância econômica da requeima do tomateiro e a necessidade de viabilizar novas estratégias para o seu manejo, este trabalho teve por objetivo avaliar a ação do fosfito de potássio isolado, em mistura com fungicidas e em programas de aplicação no controle dessa doença, na produtividade e na qualidade de frutos do tomateiro.

\section{MATERIAL É MÉTODOS}

\section{Experimento em casa-de-vegetação e laboratório}

Sementes dos híbridos Giuliana e Rebeca foram semeadas em vasos contendo $1,3 \mathrm{~L}$ de substrato à base de casca de Pinus. Após a germinação, foi realizado o desbaste, mantendo duas plântulas por vaso. As aplicações dos tratamentos iniciaram-se no estádio de quarta folha em formação, sendo realizadas três pulverizações a intervalos de 7 dias. O delineamento experimental utilizado foi o inteiramente casualizado, no esquema fatorial $4 \times 4 \times 2$, ou seja,

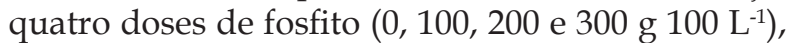
quatro tratamentos com fungicidas [sem fungicida, mancozebe (300 g $\left.100 \mathrm{~L}^{-1}\right)$, fenamidona $\left(15{\left.\mathrm{~g} 100 \mathrm{~L}^{-1}\right)}^{-1}\right.$ e metalaxil-M + mancozebe (300 g $\left.100 \mathrm{~L}^{-1}\right)$ ] e duas variedades de tomate (Giuliana e Rebeca), com quatro repetições cada, onde cada parcela continha 4 vasos com duas plantas.

Cerca de quarenta e oito horas após a última aplicação dos tratamentos com fungicidas, discos foliares de 1,0 cm de diâmetro foram coletados ao acaso e transferidos para placas de Petri revestidas de papel de filtro umedecido com água destilada. Logo após, cada disco foliar foi inoculado com 10 $\mu \mathrm{L}$ de uma suspensão com $10^{4}$ esporângios de $P$. infestans $\mathrm{mL}^{-1}$, sendo as placas foram incubadas mantidas em BOD a $18^{\circ} \mathrm{C}$ e fotoperíodo de 12 horas por sete dias. As avaliações de severidade da doença nos discos foliares foram realizadas no quarto e sétimo dia após a inoculação, através de uma escala diagramática: 1 - ausência de sintomas; 2 - traços a $12,5 \% ; 3-12,6$ a $25 \% ; 4-25,1$ a $50 \%$ e 5 - acima de $50 \%$ de área foliar lesionada. Na segunda avaliação, também foi considerada a porcentagem de área do disco coberta por esporulação típica de $P$. infestans (0 a 100\%) em todos os discos.

\section{Experimentos em campo}

Os experimentos foram instalados no Município de Pilar do Sul, SP, no período de maio a julho de 
2008, no híbrido de tomate Alambra, um dos mais plantados no campo para a produção de tomate de mesa. O delineamento experimental utilizado foi o de blocos ao acaso com 12 e 14 tratamentos, nos experimentos 1 e 2 , respectivamente, com quatro repetições, sendo cada parcela composta por 24 plantas.

Os tratamentos testados (g ou $\mathrm{mL}$ de p.c. 100 $\mathrm{L}^{-1}$ de água) no experimento 1 , foram: 1 - clorotalonil (300)/metalaxil M + mancozebe (300)/ propamocarbe (150) - programa padrão $1 ; 2$ - clorotalonil (300)/metalaxil-M + mancozebe (300)/ propamocarbe(150) + fosfito de potássio (100); 3 clorotalonil (300)/ metalaxil-M + mancozebe (300)/ propamocarbe (150) + fosfito de potássio (200); 4 - clorotalonil (300)/metalaxil M + mancozebe (300)/ propamocarbe (150) + fosfito de potássio (300); 5 - fenamidona (15)/cimoxanil + mancozebe (300)/ iprovalicarbe + propinebe (250) - programa padrão 2; 6 - fenamidona (15)/ cimoxanil + mancozebe (300) / iprovalicarbe + propinebe (250) + fosfito de potássio (100); 7 - fenamidona (15)/cimoxanil+mancozebe (300)/iprovalicarbe + propinebe (250) + fosfito de potássio (200); 8 - fenamidona (15)/cimoxanil + mancozebe (300)/iprovalicarbe + propinebe (250) + fosfito de potássio ( $300 \mathrm{~g})$; 9 - fosfito de potássio (100); 10 - fosfito de potássio (200); 11 - fosfito de potássio (300) e 12 - testemunha.

$\mathrm{O}$ experimento 2 constou dos seguintes tratamentos em $\mathrm{g}$ ou $\mathrm{mL}$ de p.c. $100 \mathrm{~L}^{-1}$ de água: 1 - mancozebe (300); 2 - mancozebe (300) + fosfito de potássio (300); 3 - cimoxanil + mancozebe (300); 4 - cimoxanil + mancozebe $(300)+$ fosfito de potássio (300); 5 - dimetomorfe + clorotalonil (300); 6 - dimetomorfe+clorotalonil (300)+fosfito de potássio (300); 7 - propamocarbe (150); 8 propamocarbe (150) + fosfito de potássio (300); 9 - piraclostrobina+metiram (400); 10 - piraclostrobina + metiram (400) + fosfito de potássio (300); 11 metalaxil-M + clorotalonil (150); 12 - metalaxil-M + clorotalonil (150) + fosfito de potássio (300); 13 - fosfito de potássio (300) e 14 - testemunha.

No experimento 1 , foram realizadas três aplicações de cada tratamento na sequência estabelecida, totalizando 9 pulverizações por programa. $O$ fosfito de potássio foi aplicado nove vezes associado ou não com os fungicidas. No experimento 2, foram realizadas seis aplicações de cada tratamento.

As pulverizações foram realizadas preventivamente, sendo iniciadas aos 50 e 58 dias após o transplante, respectivamente, para os experimentos 1 e2. Para tanto, foi utilizado um pulverizador costal pressurizado a $\mathrm{CO}_{2}$, munido de lança de aplicação e pressão constante de 4 bar, regulado de forma a proporcionar cobertura adequada do alvo. A lança de aplicação era composta por 3 bicos cônicos do tipo TXKV26, espaçados de $10 \mathrm{~cm}$, sendo a distância entre a lança e o alvo durante a aplicação de aproximadamente $50 \mathrm{~cm}$. O volume de aplicação variou de 600 a $1.000 \mathrm{~L} \mathrm{ha}^{-1}$, em função do desenvolvimento da cultura. Os intervalos de aplicação foram de 7 a 10 dias no experimento 1 e de 7 a 9 dias no 2. No período prévio e posterior às aplicações dos tratamentos, foram realizadas pulverizações de manutenção com clorotalonil (1,5 kg de p.c. ha- $\left.{ }^{-1}\right)$, em ambos os experimentos.

Os critérios de avaliação adotados nos 2 experimentos foram: a) severidadeem folhas, determinada pela análise visual da porcentagem de área foliar afetada pela doença, na faixa de 0 a $100 \%$, a partir dos primeiros sintomas. Foram realizadas seis avaliações a partir dos 72 dias após o transplante a intervalos de 5 a 7 dias. Com os valores obtidos calculou-se a área abaixo da curva de progresso da requeima (CAMPBELL; MADDEN, 1990). Os valores foram padronizados, dividindo-se cada valor pelo numero de dias da epidemia; b) ocorrência de sintomas na haste, através de escala de notas de 1 a 5 , onde se considerou: 1 -ausência de sintomas; 2 - lesões menores que $1,0 \mathrm{~cm} ; 3$ - lesões entre 1,0 e 5 cm; 4 - lesões maiores que $5 \mathrm{~cm}$ e que envolviam todo o caule (anelares); c) variáveis referentes à produção: número de frutos sadios e afetados por $P$. infestans por parcela, massa fresca de frutos sadios (g) e produtividade $\left(\right.$ ton $\left.\mathrm{ha}^{-1}\right)$.

Os dados foram submetidos à análise da variância, aplicando-se o teste de Tukey a $5 \%$ de probabilidade para a comparação das médias. Os dados de porcentagem de área foliar afetada foram previamente transformados em arc sen raiz de x/100.

\section{RESULTADOS E DISCUSSÃO}

Para a severidade da requeima, avaliada aos 4 e 7 dias após a inoculação, e porcentagem de esporulação, aos 7 dias após a inoculação, os tratamentos foram superiores à testemunha. Os cultivares Giuliana e Rebeca não diferiram significativamente entre si (Tabela 1).

No quarto e sétimo dia após a inoculação, o controle da requeima foi menos eficiente com o uso isolado de mancozebe, de fosfito de potássio ou com a mistura de ambos em relação aos demais tratamentos, para os cultivares Giuliana e Rebeca. Apenas a adição de fosfito de potássio $\left(300{\left.\mathrm{~g} 100 \mathrm{~L}^{-1}\right)}^{-1}\right.$ ao mancozebe incrementou o controle da requeima em relação ao uso de ambos isolados.

Quanto à esporulação, somente os discos foliares de tomateGiuliana e Rebeca tratados com mancozebe apresentaram esporulação de $P$. infestans, porém, em nível inferior à testemunha.

No campo, as condições climáticas favoreceram o desenvolvimento da requeima nos dois experimentos. 

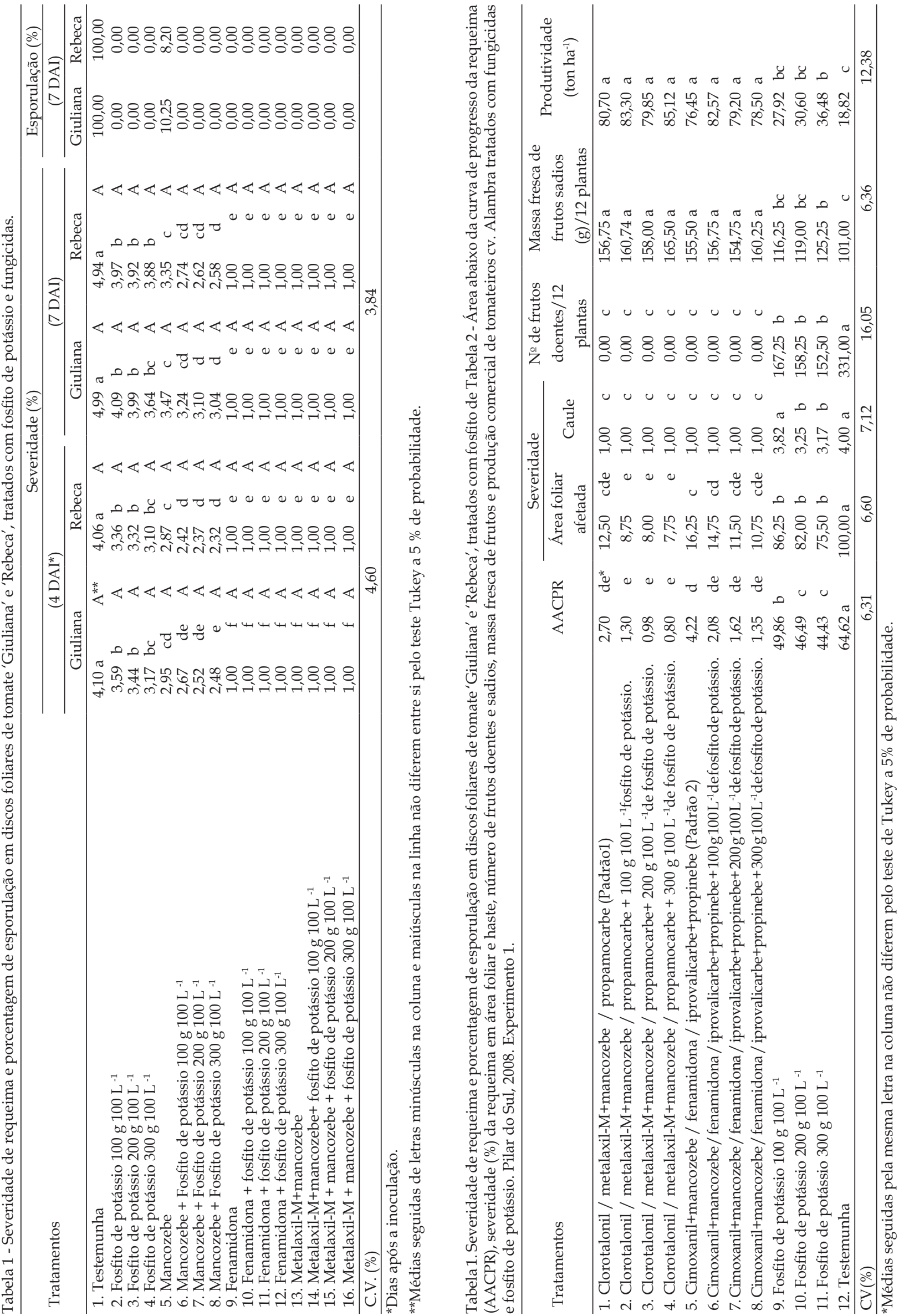


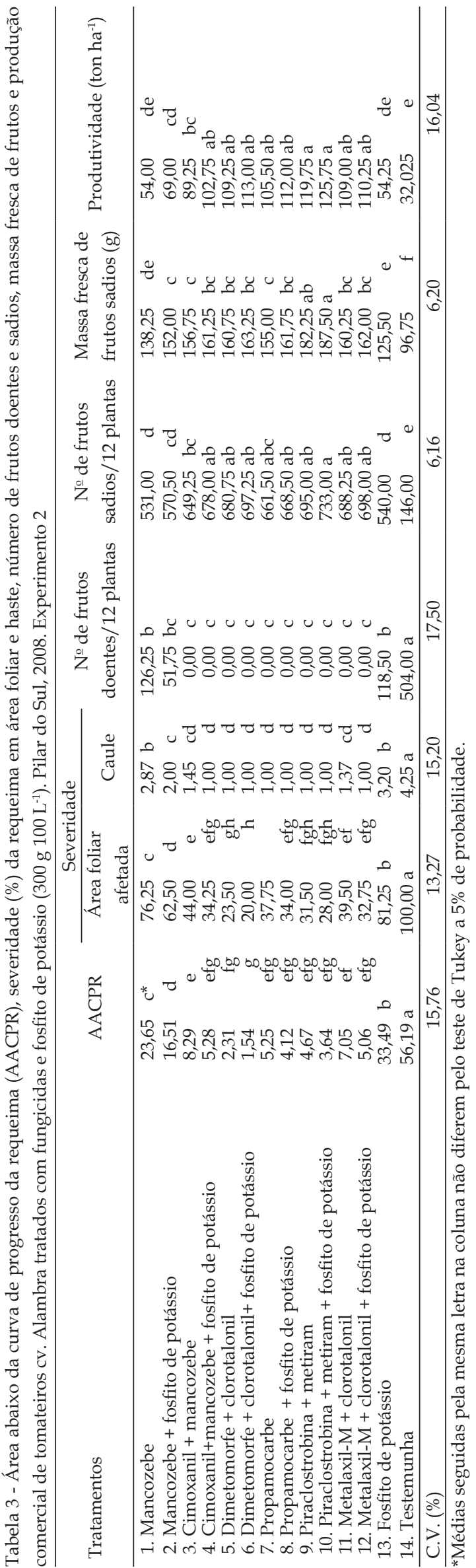

No experimento 1, a adição de 100, 200 e 300 $\mathrm{g} \mathrm{L}^{-1}$ de fosfito de potássio ao programa padrão 1 (clorotalonil/metalaxil-M + mancozebe/propamocarbe) reduziu o progresso da requeima em relação ao programa padrão 2 (cimoxanil + mancozebe) fenamidona/iprovalicarbe + propinebe) eà aplicação isolada do fosfito de potássio (Tabela 2).

A severidade da doença variou de 8 a 100\% nas folhas e as notas de 1 a 4 no caule. Os programas referentes ao uso de clorotalonil/metalaxil-M + mancozebe/propamocarbe (programa 1) e de Cimoxanil + mancozebe/fenamidona/iprovalicarbe + propinebe (programa 5), associados ou não com fosfito de potássio, reduziram a severidade da requeima, tanto nas folhas como nos caules, quando comparado ao uso isolado de fosfito.

Quanto à área foliar afetada, o programa clorotalonil/metalaxil-M + mancozebe/propamocarbe associados com fosfito foi superior ao programa cimoxanil + mancozebe/fenamidona/iprovalicarbe + propinebe associado ou não com $100 \mathrm{~g} \mathrm{~L}^{-1}$ de fosfito de potássio e à aplicação isolada desse último. Para o caule, todos os programas foram semelhantes entre si, mas superiores ao uso isolado de fosfito de potássio (Tabela 2).

A presença de frutos doentes foi observada somente nas parcelas testemunhas e naquelas que receberam o fosfito de potássio. Entretanto, esse produto reduziu, em média, $48 \%$ o número de frutos afetados por $P$. infestans e aumentou em $68 \%$ a produtividade, embora essa seja considerada ainda baixa $\left(31,7 \mathrm{t} \mathrm{ha}^{-1}\right)$.

Os programas 1 a 8 proporcionaram os maiores valores de massa fresca e de número de frutos sadios, sendo todos semelhantes entre si e superiores ao fosfito de potássio. Por outro lado, a aplicação

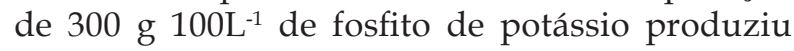
maior número de frutos sadios em relação à dose

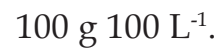

Para a massa fresca de frutos sadios e produtividade, os melhores resultados foram obtidos com os programas de 1 a 8 , sendo todos semelhantes entre si e superiores ao fosfito de potássio e à testemunha. Somente a aplicação de $300 \mathrm{~g} \mathrm{~L}^{-1}$ de fosfito de potássio foi superior à testemunha, mas a produtividade foi baixa $\left(36,48\right.$ tha $\left.^{-1}\right)$ em relação às obtidas pelas aplicações de fungicidas associados ou não com o fosfito.

No experimento 2, a aplicação de fungicidas associados ou não com fosfito de potássio reduziram o progresso da requeima em relação à aplicação isolada de fosfito de potássio e à testemunha. $\mathrm{O}$ uso de dimetomorfe + clorotalonil foi mais eficiente no controle da doença que as aplicações de mancozebe, mancozebe + fosfito de potássio; cimoxanil + mancozebe e metalaxil-M + clorotalonil (Tabela 3).

A severidade da requeima nas folhas foi reduzida com as aplicações de dimetomorfe + cloro- 
talonil associados ou não com fosfito de potássio em relação aos demais tratamentos, com exceção do piraclostrobina + metiram com ou sem fosfito de potássio e metalaxil-M + clorotalonil + fosfito de potássio. No caule, o mancozebe e a aplicação isolada de fosfito de potássio não foram eficientes no controle da doença, cuja severidade alcançou notas 2,87 e 3,20, respectivamente. Entretanto, a associação desses produtos promoveu nível superior de controle da requeima em relação ao uso isolado deles (Tabela 3).

Frutos afetados pela requeima foram observados nas parcelas pulverizadas com mancozebe, mancozebe + fosfito de potássio e fosfito de potássio, todavia em níveis bem inferiores à testemunha.

Piraclostrobina + metiram+fosfito de potássio proporcionou maior numero de frutos sadios, em relação aos tratamentos mancozebe, mancozebe + fosfito de potássio, cimoxanil + mancozebe e fosfito de potássio, sendo todos superiores à testemunha.

A maior massa de frutos também foi obtida com piraclostrobina + metiram + fosfito de potássio em comparação aos demais tratamentos, com exceção desses fungicidas sem o uso de fosfito de potássio. As parcelas tratadas com mancozebe ou com fosfito de potássio produziram os frutos com menor massa fresca, sendo, porém, semelhantes entre si. A mistura de ambos, por sua vez, foi benéfica, aumentando em 9,9, e $21,1 \%$ ovalor dessa variável, quando comparado com os valores obtidos pela aplicação isolada deles.

Os tratamentos piraclostrobina + metiram e piraclostrobina + metiram + fosfito de potássio foram superiores ao mancozebe, mancozebe + fosfito de potássio, cimoxanil +mancozebe e fosfito de potássio quanto à produtividade, porém semelhantes aos demais tratamentos. Mancozebee fosfito de potássio foram responsáveis por produções semelhantes entre si e à testemunha.

A redução da severidade da requeima proporcionada pelo fosfito de potássio em condições de casade-vegetação observada neste trabalho também foi verificada por ANDREU; CALDIZ (2006) na cultura da batata. Os autores concluíram que as aplicações de fosfito de cálcio na cultivar Kennebeck e de fosfito de potássio no cultivar Shenopody foram capazes de reduzir a severidade da requeima em condições controladas.

A ausência de esporulação nos discos foliares de tomateiro inoculados com $P$. infestans e tratados com fosfito de potássio evidencia uma característica complementar importante no controle por reduzir o potencial de inóculo para futuros ciclos da doença. (CAMPBell; MAdDEN, 1990).

Apesar da menor severidade e um menor progresso da doença nos tratamentos com fosfito de potássio isolado, o nível de doença no campo foi considerado alto quando comparado com fungicidas específicos. Estes resultados concordam com os obtidos por OuimetTe; Coffey (1989) onde os fosfitos não promoveram controlecompleto deinfecções causadas por Phytophthora spp. Para NAscimento et al. (2008), as aplicações de fosfitos não reduziram suficientemente a requeima no tomateiro para serem considerados efetivos. Resultados semelhantes foram obtidos por BECKTELl et al. (2005) onde o uso de fosfito de potássio não proporcionou controle satisfatório de $P$. infestans.

Para os critérios severidade da requeima nas folhas e no caule, número de frutos doentes e sadios, o fosfito de potássio isolado foi eficiente em relação à testemunha, nos dois experimentos (Tabelas $2 \mathrm{e} 3$ ). A massa fresca de frutos sadios e a produtividade aumentaram com a aplicação de fosfito de potássio, entretanto, no experimento 1 somente a dose

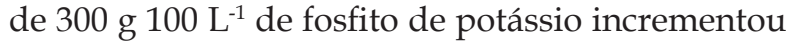
esses critérios. A eficácia do fosfito de potássio em reduzir a requeima nas culturas de tomate e batata com reflexos positivos sobre a produtividade equalidade foi observada por MACNAB (2004) e MAYTON et al. (2008), respectivamente.

$\mathrm{O}$ controle da requeima em laboratório e em campo foi maior pela mistura de fosfito de potássio com mancozebe, em relação à aplicação isolada desses produtos. Tal resultado deve-se provavelmente às características dos fungicidas testados. Os fungicidas metalaxil-M, fenamidona, piraclostrobina, propamocarbe, dimetomorfe e cimoxanil por possuírem diferentes níveis de sistemicidade, maior ação fungitóxica e tenacidade inerente não tiveram desempenho superior com a adição do fosfito de potássio. Por outro lado, quando o fosfito de potássio foi utilizado em mistura com mancozebe, que apresenta ação protetora limitada na superfície dos tecidos, baixa fungitoxicidade e vulnerabilidade à lavagem de seus depósitos pela ação de chuvas e água de irrigação, houve aumento significativo do controle.

No campo o aumento de controle nas parcelas tratadas com a mistura de mancozebe + fosfito de potássio (300 g $\left.100 \mathrm{~L}^{-1}\right)$, refletiu de forma positiva sobre a massa fresca de frutos e produtividade.

Os resultados obtidos neste trabalho destacam o potencial do uso de fosfito de potássio em mistura com mancozebe para o manejo da requeima do tomateiro. Essa alternativa pode ser interessante em condições de baixa pressão de doença, ou para aumentar a eficácia de controle de aplicações isoladas desse fungicida em sistemas de produção integrada.

\section{REFERÊNCIAS}

ANDREU, A.B.; CALDIZ, D.O. El uso de fosfitos y su contribución al control de tizón tardio y Fusarium spp. Del Campo a la Fabrica, v.6, p.3-7, 2006. 
ANDREU, A.; GUEVARA M.G.; WOLSKI, E. DALEO G.; D. CALDIZ. Enhancement of the natural disease resistance of potatoes by chemicals. Pest Management Science, v.62, p.162-170, 2006.

BASHAN, B.; LEVY, Y.; COHEN, Y. Variation in sensibility of Phytophthora infestans to fosetyl-Al. Plant Pathology, v.39, p.134-140, 1990.

BECKTELL, M.C.; DAUGHTREY, M.L.; FRY, W.E. Epidemiology and management of petunia and tomato late blight in the greenhouse. Plant Disesase, v.89, p.1000-1008, 2005.

BECOT, S.; PAJOT, E.; LE CORRE, D.; MONOT, C.; SILUÉ, D. Phytogard $\left(\mathrm{K}_{2} \mathrm{HPO}_{3}\right)$ induces localized resistance in cauliflower to downy mildew of crucifers. Crop Protection, v.19, p.417-425, 2000.

BROWN, S.; KOIKE; S. T.; OCHOA, O. E.; LAEMMLEN, F.; MICHELMORE, R. Insensitivity to the fungicide fosetyl-aluminium in California isolates of the lettuce downy mildew pathogen, Bremia lactucae. Plant Disease, v.88, p.502-508, 2004.

CAMPBELL, C.L.; MADDEN, L.V. Introduction to plant disease epidemiology. New York: John Wiley, 1990. 532p.

COFFEY, M.D.; BOWER, L.A. In vitro variability among isolates of eight Phytophthora species in response to phosphorous acid. Phytopathology, v.74, p.738-742, 1984.

COHEN, M.D.; COFFEY, M.D. Systemic fungicides and the control of oomycetes. Annual Review of Phytopathology, v.24, p.311-338, 1986.

FENN, M.E.; COFFEY, M.D. Studies on the in vitro and in vivo antifungal activity of Fosetyl-Al and Phosphorous acid. Phytopathology, v.74, p.606-611, 1984.

FENN, M.E.; COFFEY, M.D. Further evidence for direct mode of action of fosethyl-al and phosphorous acid. Phytopathology, v.75, p.1064-1068, 1985.

FÖRSTER, H.; ADASCAVEG, J. E.; KIM, D. H.; STHANGELLINE, M.E. Effect of phosphite on tomato and pepper plants and on susceptibility of pepper to Phytophthora root and crown rot in hydroponic culture. Plant Disease, v.82, p.1165-1171, 1998.

GUEST, D.I.; GRANT, B.R. The complex action of phosphonates as antifungal agents. Biological Review, v.66, p.159-187, 1990.

IRVING, H.R.; KÚC, J. Local and systemic induction of peroxidase, chitinase and resistance in cucumber plants by $\mathrm{K}_{2} \mathrm{HPO}_{4}$. Physiological and Molecular Plant Pathology, v.37, p.355-366, 1990.

JACKSON, T.J.; BURGESS, T.; COLQUHOUN, I.; HARDY, G.E. Action of the fungicide phosphite on
Eucalyptus marginata inoculated with Phytophthora cinnamomi. Plant Pathology v.49, p.147-154, 2000.

JOHNSON, D.A.; INGLIS, D.A. MILLER, J.S. Control of potato tuber rots caused by oomycetes with foliar applications of phosphorous acid. Plant Disease, v.8, p.1153-1159, 2004.

KUROZAWA, C.; PAVAN, M.A.. Doenças do Tomateiro (Lycopersicon esculentum). In: KIMATI et al. (Ed.) Manual de Fitopatologia. São Paulo: Agronômica Ceres, v.2, 2005. p.608-626.

LOPES, C.A.; AVILA, A.C. Doenças do tomateiro. Brasília: EMBRAPA/CNPH, 2005. 151p.

LOVATT, C.J.; MIKKELSEN, R.L. Phosphites fertilizers. Better Crops with Plant Food, v.90, p.11-13, 2006.

MAYTON, H.; MYERS, K.; FRY, W.E. Potato late blight in tubers - the role of foliar phosphonate applications in suppressing pre-harvest tuber infections. Crop Protection, v.27, p.943-950, 2008.

McGRATH, M.T. What are fungicides? The plant health instructor. Disponível: <http:/ / www.apsnet.org/edication/introplantpath/topics/fungicides/pdfs.2004>. Acesso em: mar. 2010.

MacNAB, A.A. Tomato late blight and early blight control with fungicides. F \& N Tests, v.60, p.71, 2004.

NASCIMENTO, A.R.; FERNANDES, P.M.; ROCHA, M.R.; SILVA, E.A. Fontes de fosfito e acibenzolar-s-metil no controle de doenças e produtividade do tomateiro. Biosciences Journal, v.24, p.53-59, 2008.

NEMESTOTHY, G.S.; GUEST, D.I. Phytoalexin accumulation, phenylalamine ammonia lyase activity and ethylene biosynthesis in fosetyl-al treated resistant and susceptible tobacco cultivars infected with Phytophthora nicotiana, var. nicotianae. Physiological and Molecular Plant Pathology, v.37, p.207-219, 1990.

OUIMETTE, D.G.; COFFEY, M.D. Comparative antifungal activity of four phosphonate compounds against isolates of nine Phytophthora species. Phytopathology, v. 79, p.761-767, 1989.

PAJOT, E.; CORRE, D.L.; SILUÉ, D. Phytogard and DL- $\beta$-amino butyric (BABA) induce resistance to downy mildew (Bremia lactuce) in lettuce (Lactuca sativa L.). 2001. European Journal of Plant Pathology, v.107, p.861-869, 2001.

REBOLLAR-ALVITER, A.; WILSON, L.L.; MADDEN, L.V.; ELLIS, M.A. A comparative evaluation of post-infection efficacy of mefenoxam and potassium phosphite with protectant efficacy of azoxystrobin and potassium phosphite for controlling leather rot of strawberry caused by Phytophthora cactorum. Crop Protection, v.29, n.4, p.349-353, 2010. 
RIBEIRO JUNIOR, P.M.; RESENDE, M.L.V.; PEREIRA, R.B.; CAVALCANTI, F.R.; AMARAL, D.R.; PADUA, M.A. Fosfito de potássio na indução de resistência a Verticilium dahlie em mudas de cacaueiro. Ciência Agrotécnica, v.30, p.629-636, 2006.

SAINDRENAN, P.; BARCHIETTO, T.; BOMPEIX, G. Effects of phosphonate on the elicitor activity of culture filtrates of Phytophthora cryptogea in Vigna unguiculate. Plant Science, v.67, p.245-251, 1990.

SMILLIE, R.; GRANT, B.R.; GUEST, D. The mode of action of phosphite: Evidence for both direct and indirect modes of action on three Phytophthora spp. in plants. Phytopathology, v.79, p.921-926, 1989.
TÖFOLI J.G.; DOMINGUES R.J.; GARCIA JUNIOR, O. Controle da requeima do tomateiro com fungicidas e seus reflexos na produção. Arquivos Instituto Biológico, São Paulo, v.70, n.4, p.473-482, 2003.

WICKS, T.J.; MARGAREY, P.A.; BOER, R.F.; PEGG, K.G. Avaliación del fosfito potásico como fungicida en Austrália. Conferencia de Brighton para la Protección de Las Cosechas - Pestes y Enfermedades, 1990.

Recebido em 5/8/10

Aceito em 14/5/12 